\title{
Polymicrobial community-acquired pneumonia requiring mechanical ventilation: A case series
}

\author{
Piroddi Ines Maria Grazia, Cilloniz Catia ${ }^{1}$, Karina Flores ${ }^{2}$, Nicolini Antonello \\ Respiratory Diseases Unit, Hospital of Sestri Levante, Genova, Italy, ${ }^{1}$ Department of Pneumology, Institut Clinic del Tórax, Hospital \\ Clinic of Barcelona - Institut d'Investigacions Biomèdiques August Pi i Sunyer, University of Barcelona, SGR 911, Ciber de Enfermedades \\ Respiratorias (Ciberes), Barcelona, Spain, ${ }^{2}$ Facultad de Medicina, Benemerita Universidad Autonoma de, Puebla, Mexico
}

Address for correspondence:

Dr. Nicolini Antonello, Respiratory Diseases Unit, via Terzi 43, 16039 Sestri Levante, Italy.

E-mail: antonellonicolini@gmail.com

\begin{tabular}{|c|l|}
\hline Access this article online & \\
\hline Quick Response Code: & \multirow{2}{*}{ Website: } \\
\hline www.caijournal.com \\
\cline { 2 - 2 }
\end{tabular}

\begin{abstract}
Polymicrobial pneumonia may cause by combinations of respiratory viruses and bacteria in a host. Colonization by Streptococcus pneumoniae was associated with increased risk of Intensive Care Unit admission or death in the setting of influenza infection whereas the colonization by methicillin resistant Staphylococcus aureus coinfection was associated with severe disease and death in adults and children. The principal association of pathogens in community-acquired pneumonia (CAP) is bacteria and viral coinfection and accounts approximately on $39 \%$ of microbiological diagnosed cases of CAP. The emergency of influenza virus $\mathrm{H} 1 \mathrm{~N} 1$ in 2009 caused the first pandemic in more than 40 years. Several studies found bacterial coinfection in a quarter and one-half of influenza infections, the pathogens more frequent isolates were $S$. pneumoniae and $S$. aureus mixed pneumonia in all patient groups. The high rate of viral bacterial infection in CAP, should suggest the consideration of new treatments, also during influenza season, the rapid detection of influenza virus (A or B) may allow physician the effective use of neuraminidase inhibitors within $36-48 \mathrm{~h}$ of symptoms onset, reducing the complication of secondary bacterial infection. On the other hand, prevention of mixed infection by influenza and pneumococcal vaccine should be addressed. The differential clinical diagnosis between a viral and a bacterial CAP is not easy: No clinical signs or radiological findings help the clinician to suspicious the diagnosis. In this case series, we report five different cases of severe polymicrobial CAP: All of them required mechanical ventilation: Invasive the first two and noninvasive ventilation the last three cases.
\end{abstract}

Key words: Mechanical ventilation, noninvasive ventilation, polymicrobial community-acquired pneumonia, severe respiratory failure

\section{INTRODUCTION}

The $2009 \mathrm{HlNl}$ virus rapidly spread to several countries, and in July 2009, the World Health Organization declared that

\begin{abstract}
This is an open access article distributed under the terms of the Creative Commons Attribution-NonCommercial-ShareAlike 3.0 License, which allows others to remix, tweak, and build upon the work non-commercially, as long as the author is credited and the new creations are licensed under the identical terms.
\end{abstract}

For reprints contact: reprints@medknow.com

How to cite this article: Grazia PI, Catia C, Flores K, Antonello N. Polymicrobial community-acquired pneumonia requiring mechanical ventilation: A case series. Community Acquir Infect 2015;2:97-102. 
infections due to $2009 \mathrm{HlNl}$ virus had reached pandemic level. ${ }^{[1]}$

As the pandemic of $2009 \mathrm{HlNl}$ influenza A virus progressed complicated with pneumonia, more patients required hospitalization. ${ }^{[2]}$

Pandemic influenza virus has been implicated in serious lower airways illness and death in subjects both with and without underlying medical conditions. ${ }^{[3]}$

Bacterial pneumonia in association with influenza has been considered an important factor leading to poor patient outcomes in prior pandemics. ${ }^{[2]}$

Community-acquired pneumonia (CAP) is the leading cause of death from infectious diseases. The mortality rates are approximately $1 \%$ for outpatients and as high as $14 \%$ for hospitalized patients; mortality rates are even higher for those who require hospitalization in Intensive Care Units (ICU). $\cdot{ }^{[4,5]}$

The role of bacterial coinfection in complicating the clinical course of HlNl influenza virus-associated pneumonia is poorly known, although it is often considered a cause of excess morbidity and mortality in $\mathrm{CAP}^{[6]}$ Bacterial coinfection is known to increase the severity of $\mathrm{HlNl}$ influenza. Past pandemics have been associated with Staphylococcus aureus which can lead to severe infection. Increasingly coinfection with Streptococcus pneumoniae has been recognized with $\mathrm{HlNl}$ influenza. ${ }^{7]}$

Bilateral pneumonia is a risk factor for the need for respiratory support and death. Development of respiratory complications confers further risk of morbidity.

Traditionally, viral pneumonia is considered less severe than bacterial CAP. However, with the influenza A HlNl outbreak in 2009, this assertion underwent a significant change because most of the infected individuals progressed to acute respiratory distress syndrome (ARDS) and in many cases, death. ${ }^{[8,9]}$

Acute viral pneumonia is an important cause of acute lung injury (ALI), although not enough is known about the exact incidence of viral infection in ALI. Polymerase chain reaction-based assays, direct fluorescent antigen assays, and viral cultures can detect viruses in samples from the human respiratory tract, but the presence of the virus does not prove it to be a pathogen, nor does it give information regarding the interaction of viruses with the host immune response and bacterial flora of the respiratory tract. The severe acute respiratory syndrome cause by $\mathrm{HlNl}$ influenza pandemic provided a better understanding of how viral pathogens mediate lung injury. Although the virus initially infects the respiratory epithelium, the relative role of epithelial damage and endothelial dysfunction has not been well-defined. The inflammatory host immune response to $\mathrm{HlNl}$ infection is a major contributor to lung injury. The lessons learned from the pandemic outbreaks of $\mathrm{HlNl}$ capture key principles of virally mediated ALI. There are pathogen-specific pathways underlying virally mediated ALI that converge onto a common end pathway resulting in diffuse alveolar damage. In terms of therapy, lung protective ventilation is the cornerstone of supportive care. There is little evidence that corticosteroids are beneficial, and they might be harmful. Future therapeutic strategies may be targeted to specific pathogens, the pathogenetic pathways in the host immune response, or enhancing repair and regeneration of tissue damage. ${ }^{[10]}$

ARDS is defined as an acute inflammatory syndrome characterized with bilateral parenchymal lung infiltrates on chest radiograph and $\mathrm{PaO}_{2} / \mathrm{FiO}_{2}$ ratio $<200$ resulting from causes other than acute left ventricular dysfunction. Inflammatory lung lesions may be induced by different disorders, with sepsis being the leading cause of ARDS. ${ }^{[1]}$

Influenza $\mathrm{A} / \mathrm{H} 1 \mathrm{Nl}$ infection seems to be responsible for the development of extremely severe type of ARDS with poor response to routine treatment. Despite great progress in the management of ARDS with novel agents and sophisticated techniques, including antimicrobial drugs, extracorporeal membrane oxygenation (ECMO), prostaglandins, nitric oxide, prostacyclin, exogenous surfactant administration, and activated protein C, supportive treatment-based mostly on advanced mechanical ventilation in the ICU seems to be the most important for the prognosis.

As already mentioned significant fraction of seasonal and in particular pandemic influenza deaths are attributed to secondary bacterial infections. The dysregulated inflammation process caused by viral and bacterial factors produced in pneumonia in the lungs contribute to the pathogenesis of polymicrobial infection and predisposition of the host to a secondary bacterial infection.

Pandemic 2009 influenza A (HlNl) virus infection has been shown to affect lower airways causing serious illness and death in patients with underlying medical conditions such as asthma, diabetes, heart, lung, and neurological diseases and pregnancy. Similar outcomes have been reported in previously healthy individuals although predictive factors for severe disease in this patient group have not been identified. ${ }^{[3]}$

We report five different cases of severe polymicrobial CAP: All of them required invasive mechanical ventilation (IMV) the first two or noninvasive ventilation (NIV) ventilation the last three cases. 


\section{CASE REPORTS}

\section{Case 1: Streptococcus pneumoniae + influenza virus A (H1N1)}

A 43-year-old man, presented on January 2011 at the Emergency Department (ED) for 6-day history of fever, cough, and progressive dyspnea. He presented with acute respiratory failure (ARF) $\left(\mathrm{FiO}_{2}, 50 \%\right)$ and septic shock. Physician started NIV and the patient presented current alcohol abuse and no comorbidities. Chest X-ray showed alveolar opacity in the upper right lobe (URL) at admission [Figure 1], in the next $24 \mathrm{~h}$ there were a progression of infiltrates and a new radiological control showed bilateral infiltrates. The laboratory studies on admission revealed elevated C-reactive protein $21.5 \mathrm{mg} / \mathrm{dL}$, leukocytes $19.0 \times 10^{9} / \mathrm{L}$ with neutrophils $75 \%$, and lymphocytopenia $2 \%$. Empirical therapy was started with levofloxacin + amoxicillin/clavulanate. Blood culture, urinary antigen, and sputum sample taken at admission were negative, nasopharyngeal swab was positive for influenza A virus $\mathrm{HlNl}$, tracheal aspirate was positive for $S$. pneumoniae. On day 2, the patient needed IMV for progressive ARF. Oseltamivir was added and change the antibiotic regimen to piperacilin tazobactam + levofloxacin.

New chest X-ray in the next $48 \mathrm{~h}$ showed ARDS despite the patients have $\mathrm{FIO}_{2} 100 \%$ and positive end expiratory pressure (PEEP) $14 \mathrm{cmH}_{2} \mathrm{O}$ in prone position.

On day 4, ECMO was started with improving of respiratory assessment. On day 9, the patient presented renal failure (creatinine $2.1 \mathrm{mg} / \mathrm{dL}$ ), hepatic insufficiency (aspartate aminotransferase 12,339 AU/L, alanine transaminase $1684 \mathrm{AU} / \mathrm{L}$ ), and lactate dehydrogenase 29,314 AU/L, hemofiltration was started.

Finally, the patient presented clinical deterioration with refractory respiratory insufficiency, hemodynamic instability, and multiorganic failure and died on day $15^{\text {th }}$.

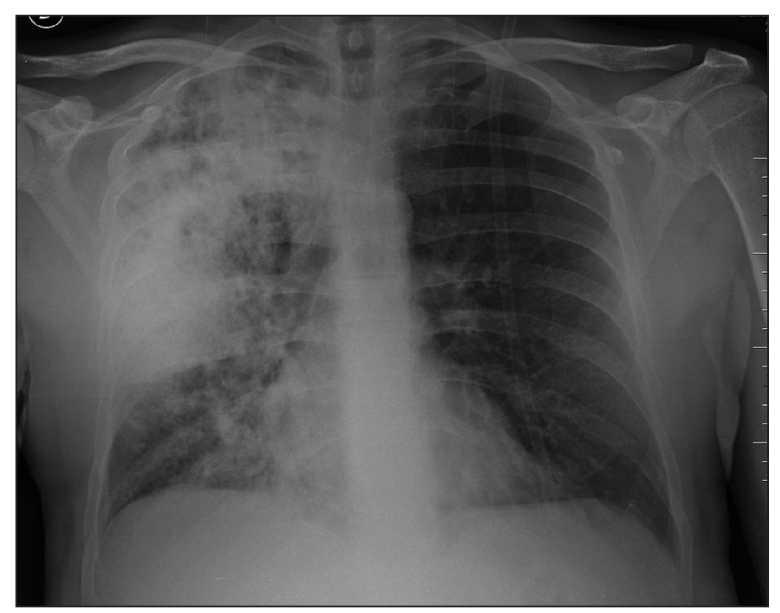

Figure 1: Chest X-ray - alveolar opacity in the upper right lobe
Case 2: Pseudomona aeruginosa multi-drug

resistant + influenza virus A H1N1 +

\section{Stenotrophomona maltophilia}

A 78-year-old woman, presented on January 2015 at the ED for 10-day history of fever, cough with purulent expectoration, and progressive dyspnea. The patient presented arterial hypertension, insulin dependent diabetes mellitus, chronic cardiac disease, and severe obesity.

On admission physical examination revealed tachypnea (breathing frequency breaths $44 \mathrm{~m}$ '). Laboratory data revealed marked elevation of inflammation and infectious parameters (leukocytes $20.10 \times 10^{9} / \mathrm{L}$, with neutrophils $77 \%$, lymphocytes 13\%, C-reactive protein $13 \mathrm{mg} / \mathrm{dL}$, sodium 137 $\mathrm{mEq} / \mathrm{L}$, and potassium $4.3 \mathrm{mEq} / \mathrm{L}$ ). Arterial blood gases $(A B G)$ analysis showed hypoxemic respiratory failure $\left(\mathrm{PaO}_{2}\right.$ $55 \mathrm{mmHg}, \mathrm{PaCO}_{2} 35 \mathrm{mmHg}$, and $\mathrm{pH}$ 7.33). The chest $\mathrm{X}$-ray revealed an infiltrate in the right lower lung and one in left lower lung, [Figure 2]. In the next $24 \mathrm{~h}$, there was a progression of infiltrates with ARDS and NIV was started. Empirical therapy was started with levofloxacin $500 \mathrm{mg} / 12$ $\mathrm{h}+$ ceftriaxone $2 \mathrm{~g} / 24 \mathrm{~h}$. Blood culture, urinary antigen, and sputum sample taken at admission were negative, nasopharyngeal swab was positive for influenza A virus HlNl, bronchoaspirate was positive for multi-drug resistant (MDR) Pseudomonas aeruginosa. Oseltamivir was added and the antibiotic regimen changed to meropenem $1 \mathrm{~g} / 8 \mathrm{~h}$ + levofloxacin. Patient presented respiratory failure, septic shock, and IMV was started.

Acute renal failure occurred (creatinine 1.66). Hemofiltration was started on day 3 . The patient was in prone position.

On day 5 , fibrobronchoscopy was necessary, obstructing mucus with blood was found and removed. Hemofiltration was stopped, and chest X-ray showed improving of infiltrates. On day 12 , the patient was extubated but in the next $48 \mathrm{~h}$ she presented respiratory failure and required new intubation,

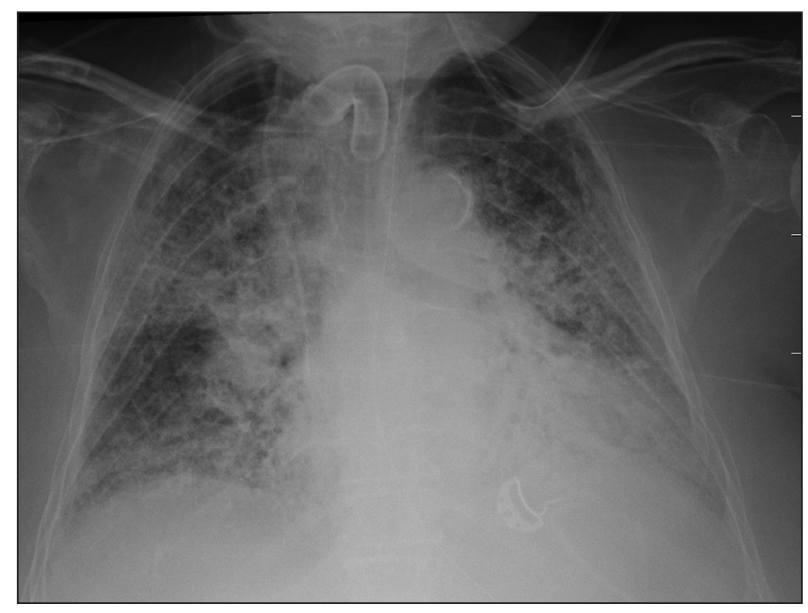

Figure 2: Chest X-ray — infiltrate in the right lower lung and one in left lower lung 
antibiotic treatment was change to linezolid + piperacillin tazobactam + amikacine. Culture of bronchoalveolar lavage was positive to P. aeruginosa and gram positive S. aureus.

Linezolid was stopped. Cryobiopsy was made and showed signs of ARDS and organization. The final results of bronchial aspirate yielded P. aeruginosa MDR and Stenotrophomona maltophilia, treatment was changed to levofloxacin and inhaled colistine.

On day 28, tracheotomy was made; and mechanical ventilation was started, patient clinical conditions worsened and she finally died on day 31 .

\section{Case 3: Legionella pneumophila + Streptococcus pneumoniae + Staphylococcus aureus}

A 57-year-old man, homeless was taken to the ED after a history of 3 day of fever $\left(39^{\circ}\right)$, cough, and purulent expectoration. He presented alcohol abuse, and untreated chronic obstructive pulmonary diseases (COPD). At admission vital signs were: Breathing frequency $38 \mathrm{~m}$, cardiac frequency 124 beats $\mathrm{m}$ ' arterial pressure $95 / 55 \mathrm{mmHg}$. Laboratory data revealed marked elevation of inflammation and infectious parameters (leukocytes $22.30 \times 10^{9} / \mathrm{L}$, with neutrophils $85 \%$, lymphocytes $9 \%$, C-reactive protein $20.06 \mathrm{mg} / \mathrm{dL}$, pro-calcitonin $2.5 \mathrm{ng} / \mathrm{mL}$ sodium $132 \mathrm{mEq} / \mathrm{L}$, and potassium $3.3 \mathrm{mEq} / \mathrm{L}$ ). Arterial blood gas analysis showed hypoxemic respiratory failure $\left(\mathrm{PaO}_{2} 45 \mathrm{mmHg}, \mathrm{PaCO}_{2}\right.$ $32 \mathrm{mmHg}$, and $\mathrm{pH} 7.49 \mathrm{PaO}_{2} / \mathrm{FiO}_{2}$ ratio 214). Chest X-ray revealed opacity in the left lung and computed tomography (CT) of the thorax showed an opacity in the left lower lobe [Figure 3]. The patient was treated with empirical therapy ceftriaxone $2 \mathrm{~g} /$ day + levofloxacin $500 \mathrm{mg}$ twice a day and oxygen via Venturi mask 50\%. The next 6 h the respiratory conditions worsened as shown by the next ABG $\left(\mathrm{PaO}_{2} 60\right.$ $\mathrm{PaCO}_{2} 42 \mathrm{pH} 7.35 \mathrm{PaO}_{2} / \mathrm{FiO}_{2}$ 120). The patient underwent NIV Bilevel PAP IPAP $15 \mathrm{cmH}_{2} \mathrm{O}$ EPAP $8 \mathrm{cmH}_{2} \mathrm{O} \mathrm{FiO}_{2} 30 \%$ with prompt improvement of gas exchange $\left(\mathrm{PaO}_{2} 75 \mathrm{PaCO}_{2}\right.$

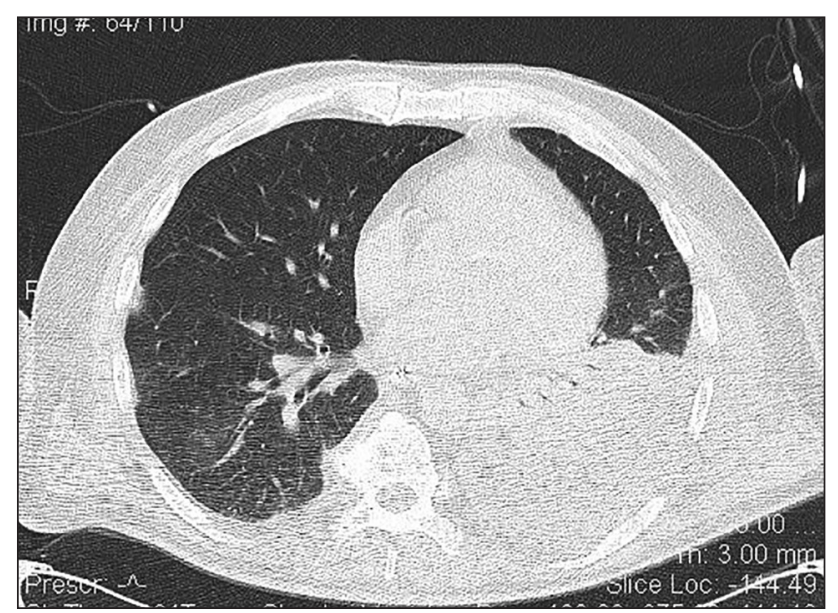

Figure 3: Computed tomography of the thorax — opacity in the left lower lobe $\left.37 \mathrm{pH} 7.37 \mathrm{PaO}_{2} / \mathrm{FiO}_{2} 250\right)$. Urinary antigen was positive both for Legionella pneumophila and S. pneumoniae. Blood culture was positive for S. pneumoniae as well Legionella antibodies. The clinical picture progressively improved. NIV was suspended after a week; after 17 days was observed a normalization of inflammation parameters (leukocytes $5.8 \times 10^{\circ} / \mathrm{L}$, C-reactive protein 0.45 ) and the patient was discharged.

\section{Case 4: Pseudomonas aeruginosa + Staphylococcus} aureus + Streptococcus agalactiae + Candida albicans A 63-year-old woman was admitted to ED complaining dyspnea, cough, purulent expectoration and fever $\left(39^{\circ}\right)$, poliuria, vomit, and diahrrea. At admission, the clinical picture was as follows: Respiratory breathing $36 \mathrm{~m}$ ' cardiac frequency 139 beats m' arterial pressure 95/45 mmHg. Laboratory data showed: Leukocytes $19.60 \times 10^{9} / \mathrm{L}$, with neutrophils $79 \%$, lymphocytes $12 \%$, C-reactive protein $18.12 \mathrm{mg} / \mathrm{dL}$, pro-calcitonin $2.0 \mathrm{ng} / \mathrm{mL}$, creatinin $1.40 \mathrm{mg} / \mathrm{dL}$ (n.v. $0.55-1.2 \mathrm{mg} / \mathrm{dL}$ ) sodium $144 \mathrm{mEq} / \mathrm{L}$, and potassium $3.4 \mathrm{mEq} / \mathrm{L}$. Arterial blood gas analysis showed hypoxemic respiratory failure $\left(\mathrm{PaO}_{2} 36 \mathrm{mmHg}, \mathrm{PaCO}_{2} 30 \mathrm{mmHg}\right.$, $\mathrm{pH}$ $7.48 \mathrm{PaO}_{2} / \mathrm{FiO}_{2}$ ratio 171$)$. Chest $\mathrm{X}$-ray and $\mathrm{CT}$ of the thorax [Figure 4] revealed an opacitiy in the medio-basal right lung zones. The patients were treated with broad spectrum empirical antibiotics (piperacillin + tazobactam $4.5 \mathrm{~g} / 8 \mathrm{~h}$ plus levofloxacin $500 \mathrm{mg} / 12 \mathrm{~h}$ ). NIV pressure support (PS) mode was implemented setting PS $10 \mathrm{cmH} 20$, PEEP $8 \mathrm{cmH} 20$ and $\mathrm{FiO}_{2} 30 \%$. The ABG performed after 1 h showed: $\mathrm{PaO}_{2}$ $74 \mathrm{PaCO}_{2} 35 \mathrm{pH} 7.39 \mathrm{PaO}_{2} / \mathrm{FiO}_{2}$ 246. A bronchoaspitate and bronchoalveolar lavage yielded: MDR P. aeruginosa, $S$. aureus, Streptococcus agalactiae, and Candida albicans. The patient changed antibiotic therapy: Tigecycline $50 \mathrm{mg} / 12 \mathrm{~h}$, colistimethate $300 \mathrm{mg} /$ day, and fluconazole $400 \mathrm{mg} /$ day. Five days later clinical picture improved: Leukocytes $8.30 \times 10^{9} / \mathrm{L}$, neutrophils $66 \%$, lymphocytes $20 \%$ C-reactive protein $3.2 \mathrm{mg} / \mathrm{dL}$, and creatinine $0.69 \mathrm{mg} / \mathrm{dL}$. ABG: $\mathrm{PaO}_{2} 68 \mathrm{PaCO}_{2}$ $38 \mathrm{pH} 7.44 \mathrm{PaO}_{2} / \mathrm{FiO}_{2} 283$ on $\mathrm{FiO}_{2} 24 \%$. NIV was suspended and patient continued oxygen therapy. Ten days later she was discharged.

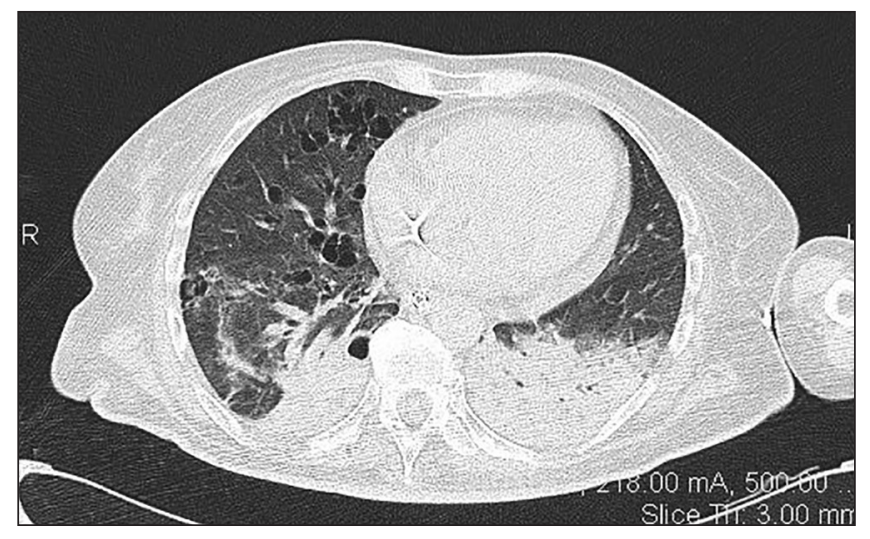

Figure 4: Computed tomography of the thorax — opacity in the medio-basal right lung zones 
Case 5: Staphylococcus aureus + Enterococcus amnigenus + Enterococcus species

A 71-year-old patient who recently underwent a surgical intervention because of lung cancer and adjuvant chemotherapy was admitted to the Respiratory Diseases Unit complaining fever $\left(38.5^{\circ}\right)$, purulent expectoration, and dyspnea. Clinical examination showed: Respiratory rate 30 cardiac frequency 112 beats m', arterial pressure $100 / 50 \mathrm{mmHg}$. ABG in air room showed severe respiratory failure: $\mathrm{PaO}_{2} 39 \mathrm{PaCO}_{2} 29 \mathrm{pH} 7.48 \mathrm{PaO}_{2} / \mathrm{FiO}_{2}$ 185. NIV was started at admission PS $12 \mathrm{cmH} 20$ PEEP $8 \mathrm{cmH} 20$ $\mathrm{FiO}_{2} 35 \%$. Chest X-ray and CT of the thorax showed an infiltrate involving the URL with a wide excavation and a small opacity at lower right lobe [Figure 5]. Laboratory findings showed: Leucocytes $10.7 \times 10^{9} / \mathrm{L}$, neutrophils $95.4 \%$, lymphocytes $1.9 \%$, C-reactive protein $25.85 \mathrm{mg} / \mathrm{dL}$, pro-calcitonin 1.6, and fibrinogen $857 \mathrm{mg} / \mathrm{dL}$ (n.v.180-450 $\mathrm{mg} / \mathrm{dL}$ ). The patient was treated initially with empirical antibiotic therapy: Ceftriaxone $2 \mathrm{~g}$ day and levofloxacin $500 \mathrm{mg}$ every $12 \mathrm{~h}$. Blood culture, urinary antigen, and sputum sample taken at admission were negative. Culture of bronchoalveolar lavage was positive for $S$. aureus methycillin resistant Enterococcus amnigenus and Enterococcus species. The three bacteria were sensitive to tygecycline which was started on day $5(50 \mathrm{mg} / \mathrm{l} 2 \mathrm{~h})$. On day 12, the patient's condition had improved and NIV was stopped. ABG showed: $\mathrm{paO}_{2} 78 \mathrm{PaCO}_{2} 39 \mathrm{pH} 7.42 \mathrm{PaO}_{2} / \mathrm{FiO}_{2} 312$ in $\mathrm{O}_{2}$ $25 \%$. Laboratory findings were: Leukocytes $8.2 \times 10^{9} / \mathrm{L}$, neutrophils $81 \%$, lymphocytes $12 \%$, and C-reactive protein $0.85 \mathrm{mg} / \mathrm{dL}$. On day 18 , the patient was discharged.

The patients alive gave the consent to publish material related to them.

\section{DISCUSSION}

The role of mixed pneumonia in CAP has been described in recent years and demonstrated that has a different inflammatory pattern compared to bacterial or viral CAP. ${ }^{[12]}$

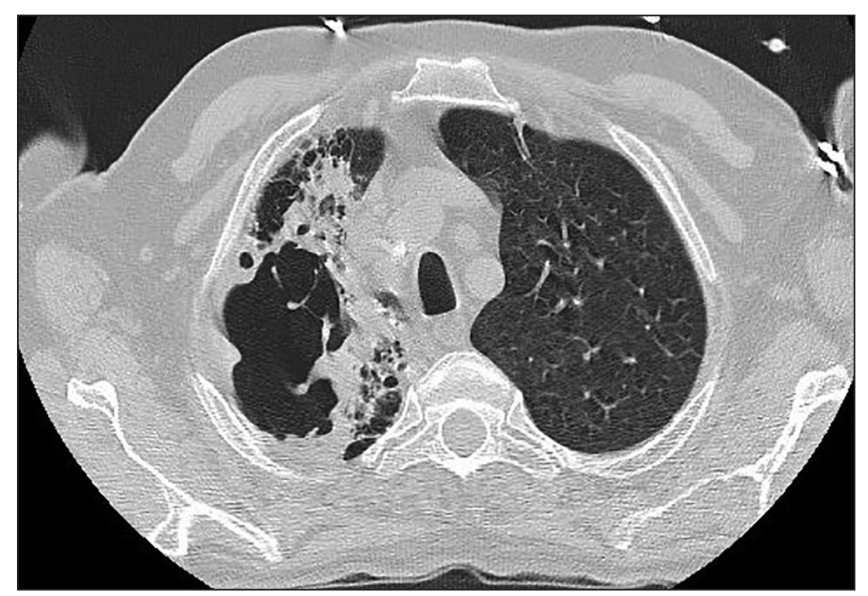

Figure 5: Computed tomography of the thorax — infiltrate involving the upper right lobe with a wide excavation
In a study conducted by Gutiérrez et al. ${ }^{[13]}$ on 493 adult patients with CAP, polymicrobial infection was found in $5.7 \%$ of patients with microbiologically confirmed diagnosis. Polymicrobial infections were seen across all age groups and in patients treated both in hospital and in outpatient clinic. The most common polymicrobial infections were $S$. pneumoniae with L. pneumophila and S. pneumoniae and Pseudomonas spp. Patients with polymicrobial infections are more likely to have underlying medical conditions and have more severe outcome. ${ }^{[14]}$ In a recent study on 1032 patients admitted with diagnosis of CAP Ishiguro et al. found in a multivariate analysis that age higher than 65, COPD, chronic heart failure, diabetes mellitus, and polymicrobial infection to be significant factors contributing to the severity of $\mathrm{CAP}^{[15]}$ S. pneumoniae was the most frequent co-pathogen in polymicrobial infections as previously reported. ${ }^{[16]}$ Moreover a study addressing polymicrobial infection in 362 patients admitted to ICU with CAP found that $11 \%$ of cases were polymicrobial and the presence of chronic respiratory disease and ARDS criteria on admission independent predictors for polymicrobial etiology. ${ }^{[17]}$ Our case series report the most frequent causative organisms in hospitalized patients: ${ }^{[18]}$ It's not clear if the severity of the clinical picture is due to polymicrobial etiology or to causative organism in itself (e.g., L. pneumophila). ${ }^{[19]}$ Undoubtedly bacterial respiratory infection is often preceded by a viral infection which favors the secondary bacterial infection caused by a pathogen colonizing the respiratory mucosa. When a viral respiratory infection occurs, this destroys the respiratory epithelium, thus increases the adhesion of bacteria to the mucosa. ${ }^{[14]}$ The same can happen for atypical bacteria. Micoses and in particular C. albicans increases the virulence of $P$. aeruginosa and allows $S$. aureus to evade phagocytosis. ${ }^{[14]}$ For clinicians, it is very important: Combined empirical antimicrobial therapy may reduce mortality: ${ }^{[19]}$ International guidelines have incorporated the idea that CAP could be due to polymicrobial agents in all patients. ${ }^{[14,19]}$ Rapid detection of influenza may allow physiacians the effective use of neuraminidase inhibitors within 36-48 h of onset of symptoms as well rapid detection of $L$. pneumophila or S. pneumoniae via urinary test. ${ }^{[20]}$ The suspicion of a polymicrobial CAP is a challenge for clinicians: Actually there is no statistically significant difference in terms of age, immunocompromised status, duration of hospitalization, laboratory parameters (except a higher level of C-reactive protein), ${ }^{[12,14]}$ and CURB-65 score between polymicrobial and isolated bacterial CAP. ${ }^{[14,21]}$ Adding molecular methods for detecting polymicrobial infections should can make diagnosis of polymicrobial CAP, therefore shorten the ICU stay or the ventilatory treatment, and improve the outcome.

\section{CONCLUSION}

Our case series suggest that polymicrobial CAP is often associated with more severe disease in adult patients. Rapid detection of the all involved pathogens is paramount 
for a correct antimicrobial therapy which allows to reduce intensive care stay or mechanical ventilation.

Few laboratory parameters may be useful to suspect a polymicrobial CAP. Further rapid molecular methods should be added to the conventional routinely methods.

\section{Financial support and sponsorship}

Nil.

\section{Conflicts of interest}

There are no conflicts of interest.

\section{REFERENCES}

1. Perez-Padilla R, de la Rosa-Zamboni D, Ponce de Leon S, Hernandez M, Quiñones-Falconi F, Bautista E, et al. Pneumonia and respiratory failure from swine-origin influenza $A(H 1 N 1)$ in Mexico. N Engl J Med 2009;361:680-9.

2. Morens DM, Taubenberger JK, Fauci AS. Predominant role of bacterial pneumonia as a cause of death in pandemic influenza: Implications for pandemic influenza preparedness. J Infect Dis 2008; 198:962-70.

3. Castillo-Palencia JP, Laflamme L, Monárrez-Espino J. Occurrence of AH1N1 viral infection and clinical features in symptomatic patients who received medical care during the 2009 influenza pandemic in Central Mexico. BMC Infect Dis 2012;12:363.

4. Mandell LA, Wunderink RG, Anzueto A, Bartlett JG, Campbell GD, Dean NC, et al. Infectious Diseases Society of America/American Thoracic Society consensus guidelines on the management of community-acquired pneumonia in adults. Clin Infect Dis 2007;44 Suppl 2:S27-72.

5. Mongardon N, Max A, Bouglé A, Pène F, Lemiale V, Charpentier J, et al. Epidemiology and outcome of severe pneumococcal pneumonia admitted to intensive care unit: A multicenter study. Crit Care 2012; 16:R155.

6. Cilloniz C, Ewig S, Menedez R, Ferrer M, Polverino E, Reyer S, et al. Bacterial co-infection with $\mathrm{H} 1 \mathrm{~N} 1$ infection in patients admitted with community acquired pneumonia. J Infect 2012;65:223-30.

7. Pedro-Botet ML, Burgos J, Lujan M, Gimenez M, Rello J, Planes A, et al. Impact of Influenza A H1N1 pandemic on invasive pneumococcal disease in adult. Scand J Infect Dis 2014;26:185-92.

8. Domínguez-Cherit G, Lapinsky SE, Macias AE, Pinto R, Espinosa-Perez L, de la Torre A, et al. Critically III patients with
2009 influenza $A(H 1 N 1)$ in Mexico. JAMA 2009;302:1880-7.

9. Nardocci P, Gullo CE, Lobo SM. Severe virus influenza A H1N1 related pneumonia and community-acquired pneumonia: Differences in the evolution. Rev Bras Ter Intensiva 2013;25:123-9.

10. Hendrickson CM, Matthay MA. Viral pathogens and acute lung injury: Investigations inspired by the SARS epidemic and the 2009 H1N1 influenza pandemic. Semin Respir Crit Care Med 2013;34:475-86.

11. Witczak A, Prystupa A, Kurys-Denis E, Borys M, Czuczwar M, Niemcewicz $M$, et al. Acute respiratory distress syndrome (ARDS) complicating influenza A/H1N1v infection - A clinical approach. Ann Agric Environ Med 2013;20:820-2.

12. Bello $S$, Mincholé E, Fandos S, Lasierra AB, Ruiz MA, Simon AL, et al. Inflammatory response in mixed viral-bacterial community-acquired pneumonia. BMC Pulm Med 2014;14:123.

13. Gutiérrez F, Masiá M, Rodríguez JC, Mirete C, Soldán B, Padilla S, et al. Community-acquired pneumonia of mixed etiology: Prevalence, clinical characteristics, and outcome. Eur J Clin Microbiol Infect Dis 2005;24:377-83.

14. Cilloniz C, Civljak R, Nicolini A, Torres A. Polymicrobial community acquired pneumonia: A new entity. Respirology 2015; [In Press].

15. Ishiguro T, Takayanagi N, Yamaguchi S, Yamakawa H, Nakamoto $\mathrm{K}$, Takaku Y, et al. Etiology and factors contributing to the severity and mortality of community-acquired pneumonia. Intern Med 2013;52:317-24.

16. Cillóniz C, Ewig S, Polverino E, Marcos MA, Esquinas C, Gabarrús A, et al. Microbial aetiology of community-acquired pneumonia and its relation to severity. Thorax 2011;66:340-6.

17. Cillóniz C, Ewig S, Ferrer M, Polverino E, Gabarrús A, Puig de la Bellacasa J, et al. Community-acquired polymicrobial pneumonia in the intensive care unit: Aetiology and prognosis. Crit Care 2011;15:R209.

18. Viasus D, Marinescu C, Villoslada A, Cordero E, Gálvez-Acebal J, Fariñas $\mathrm{MC}$, et al. Community-acquired pneumonia during the first post-pandemic influenza season: A prospective, multicentre cohort study. J Infect 2013;67:185-93.

19. Rello J, Gattarello S, Souto J, Sole-Violan J, Valles J, Peredo R, et al. Community-acquired Legionella pneumonia in the intensive care unit: Impact on survival of combined antibiotic therapy. Med Intensiva 2013;37:320-6.

20. Waterer GW, Rello J, Wunderink RG. Management of community-acquired pneumonia in adults. Am J Respir Crit Care Med 2011;183:157-64.

21. Çaglayan Serin D, Pullukçu H, Ciçek C, Sipahi OR, Tasbakan S, Atalay S; Pneumonia Study Group. Bacterial and viral etiology in hospitalized community acquired pneumonia with molecular methods and clinical evaluation. J Infect Dev Ctries 2014;8:510-8. 